\title{
A NEW SPECIES OF ANACIS FROM NORTHWEST ARGENTINA (HYMENOPTERA, ICHNEUMONIDAE)
}

\author{
By Charles C. Porter* \\ Department of Biological Sciences, Fordham University, \\ Bronx, New York 10458
}

In two previous contributions (Porter 1967, 1970), the author characterized the mesostenine ichneumonid genus Anacis, assigning to it four species from Chile and contiguous regions of southwestern Argentina. Meanwhile, Townes (1969, p. I76-I 77), as a result of his study of the world Mesostenini, enlarged the definition of Anacis to include also Cryptus exul (Turner, 1919, Ann. \& Mag. Nat. Hist. (9) 3: 558) from Tasmania. Consequently, Anacis seemed to emerge as pertaining to that zoogeographic category comprised of taxa restricted at the present time to the Nothofagus zone of southern South America and to similar areas of the Australian region.

Now, however, discovery of a fifth Neotropic Anacis from subtropical wet forest in northwestern Argentina obliges us to modify our distributional concept of the genus. Thus, in South America Anacis appears to be of Andean rather than of strictly Neantarctic or Araucanian range and, quite possibly, extends to other areas on the continent. Its New World distribution, therefore, may be compared to that of several other ichneumonid genera - such as Macrogrotea, Trachysphyrus (sensu Townes), Picrocryptoides, Dotocryptus, Deleboea, Alophophion, and Thymebatis - all of which are well represented in Andean and temperate South America, including Chile, but which concurrently have a greater or lesser number of species on the peripheries of the lowland tropics. Taxa of this same distributional type which moreover have species in the Australian region are, of course, much rarer, but the ichneumonid genus Labena (two species also reach North America) and the scolioid family Thynnidae constitute approximate parallels.

The present study offers a description of this new Argentine Anacis and a revised key to all known South American species of the genus.

\section{KEY TO THE SOUTH AMERICAN SPECIES OF ANACIS}

(Based on females)

I. Mesoscutum mat, finely granular; setae of second gastric tergite dense, mostly approaching or exceeding the length of their 
interspaces; mesosoma pale red or reddish brown with white markings and black areas of variable extent ..................... 2

Mesoscutum silky shining with more or less fine punctuation; setae of second gastric tergite sparser, mostly shorter to much shorter than the length of their interspaces; mesosoma black with sparse to profuse white markings

2. Gaster black with white apical bands on tergites; flagellum with a white annulus; hind-tarsomeres 2-4 white; first flagellomere 8.5-IO.O as long as deep at apex; postpetiole weakly expanded, o.8-0.9 as wide apically as long from spiracle to apex; ovipositor tip 0.18-0.20 as high at notch as long from notch to apex

I. A. festiva Porter

Gaster bright reddish brown with more or less prominent white apical bands on tergites; flagellum without a white annulus; hind-tarsus without white markings; first flagellomere 6.2-7.3 as long as deep at apex; postpetiole more strongly expanded, I.3-I.4 as wide apically as long from spiracle to apex; ovipositor tip 0.26-0.3I as high at notch as long from notch to apex 2. A. tucumana n. sp.

3. Thorax and propodeum with profuse white markings; all gastric tergites with a complete white apical band; apical margin of clypeus with a small subdentate median projection; dorsal margin of pronotum without a definite submarginal groove 3. A. stangeorum Porter

Mesosoma with white at most on anterior margin of pronotum, tegula, and subalarum; not all gastric tergites with a complete white apical band; no median projection on apical margin of clypeus; dorsal margin of pronotum with a conspicuous submarginal groove

4. Legs mostly black with white markings; gaster with the following white: median subapical mark on tergite $I$, sometimes marks on 2 and 3, and broad apical bands on 4-7; sheathed portion of ovipositor 0.5-0.6 as long as fore-wing; nodus of ovipositor tip with an unusually large and deep notch

4. A. varipes Porter

Legs mostly orange; gaster with white at most on tergites 6-8 and only on 7 sometimes with a complete white apical band; sheathed portion of ovipositor $0.3-0.4$ as long as fore-wing; nodus with a small but distinct notch .... 5. A. rubripes Spinola 


\section{Anacis tucumana new species ( fig. I )}

Holotype: female, ARGENTINA (Tucumán: Horco Molle, Dto. Tafí, October 24, I970, C. C. Porter). (Tucumán). Paratypes: 4 females, ARGENTINA (Jujuy: Posta de Lozano, October 26, 1969, December 8, 1969, C. C. Porter; Tucumán: Horco Molle, Dto. Tafí, September 9-i i \& September 30, 1969, C. C. Porter). (Gainesville, Porter, Tucumán).

Female: Color: flagellum pale reddish brown with slight dusky staining, especially above on first segment; pedicel largely blackish brown above and pale reddish brown to yellowish below; scape largely blackish brown above and grading through reddish brown into yellowish below; head black with some brown staining toward apex on mandibles, sometimes in malar space, often around clypeus above, often irregularly on face, and on antennal sockets, as well as with the following white: most of basal I/2 of mandible; very large transverse blotch on clypeus; and a complete or sometimes ventrally interrupted orbital ring, which is broadest below where it extends $\mathrm{I} / 2$ to $3 / 4$ or more the distance into malar space; mesosoma bright reddish brown with black on areas of variable extent including most of prothorax (which at most is irregularly reddish stained), mesoscutum slightly to entirely, mesopleuron slightly to on as much as dorsal I/3 plus most of prepectus, many margins and sutures more or less broadly, as well as with the following white: broad anterior margin of pronotum except toward apex; broad dorsal margin of pronotum except for about median $\mathrm{I} / 4-\mathrm{I} / 3$; tegula; most of subalarum; sometimes large spot toward lower anterior corner of mesopleuron; small area in upper hind corner of mesopleuron on mesepimeron; most of apical 3/4-7/8 of scutellum; and sometimes most of postscutellum; gaster bright reddish brown with a prominent to dull and little contrasting white apical band on tergites $\mathrm{I}$ or 28 ; fore-leg with coxa mostly white with a conspicuous dorso-apical brown blotch and some brown staining postero-basally; trochanter white with a large pale brown blotch dorsally; trochantellus white with dusky to black staining on apex and above; femur bright reddish brown grading into whitish below and with a little dusky to hlack staining on base; and tibia and tarsus somewhat duller brown with some faint dusky staining and with fifth tarsomere mostly dusky to blackish; mid-leg with coxa pale reddish brown with a large, pale to dark brown dorso-apical blotch and sometimes a less well defined ventral brownish area basad, as well as with white on 


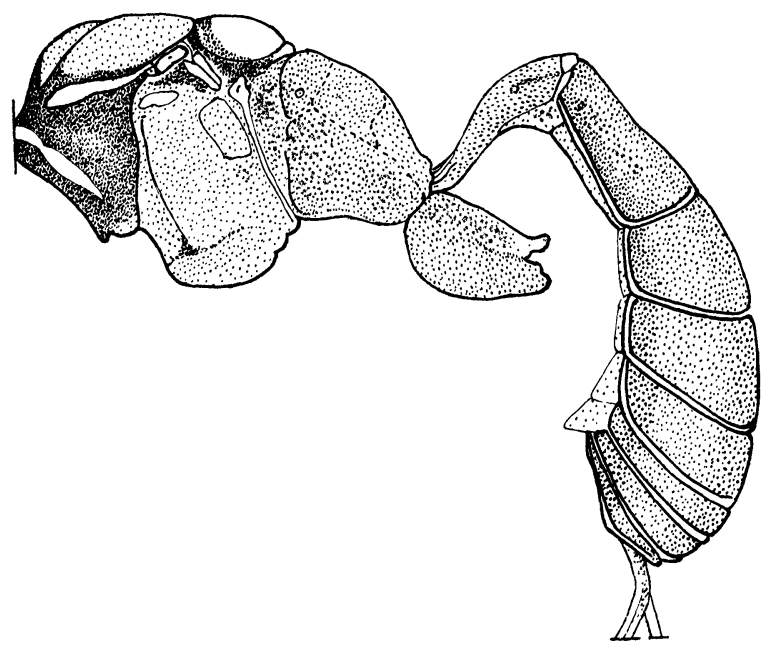

Fig. 1. Anacis tucumana Porter, female holotype. Lateral view of mesosoma and gaster, showing color pattern.

most of dorso-basal $3 / 5$ and on an extensive ventro-apical area; trochanter white with a large brown area dorsally; trochantellus white basally and below and blackish brown apically and above; femur bright reddish brown with base narrowly blackish; and tibia and tarsus a little duller reddish brown with last tarsomere dusky to blackish; hind-leg with coxa uniformly bright red brown, except sometimes for an obscure whitish area above near base; trochanter varying from white with reddish brown staining to almost uniformly reddish brown with white narrowly on apex, and sometimes with blackish frown staining on about basal $3 / 4$ above; trochantellus more or less blackish brown above and mostly reddish to brownish white or white below; femur bright red-brown with base narrowly blackish; and tibia and tarsus a little more dully red-brown with last tarsomere dusky to blackish; wings hyaline with very slight dusky staining apicad. Length of fore-wing: $5 \cdot 3-5.7 \mathrm{~mm}$. Ist flagellomere: $6.2-7.3$ as long as deep at apex. Clypeus: in profile high and asymmetrically convex to bluntly subpyramidal, with the apical face shorter than the basal and a little concavely declivous; the apical margin practically straight, not produced or dentate medially. Malar space: $0.75-0.85$ as long as basal width of mandible. Temple: 0.300.36 as long as eye in dorsal view; gently rounded-off and strongly 
receding. Fore-tibia: moderately stout but scarcely swollen. Pronotum: dorsal margin a little swollen, especially anteriad, and without a submarginal groove; epomia sharp in scrobe but only faintly prolonged below; anterior margin not angled at mid-height below. Mesoscutum: notauli traceable about $\mathrm{I} / 2-2 / 3$ the length of mesoscutum, well defined but not very sharp anteriad and becoming much weaker behind; surface mat and finely granular with abundant, small, faint, subadjacent to confluent punctures and an area of contrastingly coarser puncto-reticulation apicad between and beyond notauli. Mesopleuron: subalarum not unusually swollen or expanded; speculum swollen, mostly smooth and polished; surface otherwise more or less strongly shining with fine but moderately strong, rather uniform, obliquely longitudinal wrinkling, which becomes only slightly more irregular on lower $\mathrm{I} / 2$, and with medium-sized, variably distinct intercalated punctures which are best defined on lower $1 / 2$. Wing venation: radial cell $2.8-3.2$ as long as broad; areolet large and broad, intercubiti strongly convergent above, 2nd abscissa of radius $0.6-0.7$ as long as Ist intercubitus; 2nd recurrent vertical, at most weakly outcurved on upper $1 / 2$; disco-cubitus broadly angled or simply arched, without or rarely with a vestige of a ramellus; nervulus at least slightly antefurcal; mediella strongly arched; axillus close to hind-margin of wing. Propodeum: moderately short and high in profile, basal face gently arched and sloping rearward to join the much more steeply declivous but not sharply discrete, subequal apical face; spiracle round; basal trans-carina sharp throughout, weakly to moderately bowed forward medially, rather far from base of propodeum; apical trans-carina more or less traceable throughout, but becoming a little to, often, very weak and irregular on its broadly bowed forward median portion, laterally well defined, forming very low, sub-crescentic cristae and continuing ventrad to pleural carina; areola not defined; without lateral longitudinal carinae; surface basad of basal trans-carina shining with considerable fine wrinkling, especially mesad, and abundant, rather large, shallow, subadjacent or sparser to confluent punctures but distad of basal trans-carina uniformly mat with stronger, granularly reticulate wrinkling and puncto-reticulation. Ist gastric segment: with a low and weakly crescentic lateral flange at base; petiole moderately broad and flat; postpetiole strongly expanded and I.3-I.4 as wide apically as long from spiracle to apex; ventro-lateral carina sharp on postpetiole and about apical I/ 2 of petiole but sometimes more or less fading out toward base on petiole, or continuing sharp to base; dorso-lateral carina fine and sharp for a short distance near spiracle 
and again toward base of petiole but otherwise faint or absent; dorsal carinae absent or at most faintly suggested above spiracle. Gaster: moderately elongate fusiform; 2nd tergite dully shining to mat with fine, granularly reticulate wrinkling and abundant, medium sized to large, mostly obscure, densely intercalated punctures which emit numerous short setae that in great part approach or equal the length of their interspaces; the following tergites with somewhat longer and denser setae that mostly equal or exceed the length of their interspaces. Ovipositor: sheathed portion 0.2 as long as forewing; straight, moderately stout, strongly compressed; nodus high, with a small but sharp notch; dorsal valve in profile with a straight to slightly concave taper between notch and apex; ventral valve on tip with fine, inclivously oblique ridges; tip $0.26-0.31$ as high at notch as long from notch to apex.

\section{MALE: unknown.}

TyPEs: The holotypes and two paratypes are deposited in the collection of the Instituto Miguel Lillo, San Miguel de Tucumán, República Argentina. One paratype has been donated to the Florida State Arthropod Collection (Gainesville, Florida, USA) and a fourth paratype is in the collection of Charles C. Porter (RFD 3, Cambridge, Maryland, USA).

Discussion: Among South American species of its genus, Anacis tucumana comes closest to the Araucanian $A$. festiva, as shown by several common characters emphasized in the key. Nonetheless, that relationship is comparatively remote and tucumana has some features which set it apart from the other South American Anacis; for example, its shorter notauli, shorter second radial abscissa, less elongate propodeum, weaker dorso-lateral and dorsal carinae of the first gastric tergite, and slightly shorter ovipositor. Indeed, the northwest Argentine and Araucanian populations of Anacis probably have been out of contact since the late Tertiary and early Pleistocene Andean uplift, although it may be surmised that this is an old genus which ranged throughout the climatically and biotically more uniform South America of Pre-Andean times.

Worth noting also is the difference in abundance between the southern and northern Anacis. At least two of the southern species ( $A$. festiva and $A$. rubripes) are very common insects likely to be encountered in numbers almost any day during the growing season; whereas, $A$. tucumana only has been collected on five occasions. This circumstance coincides with the probable relict status of Anacis. Populations isolated in the Araucanian zone, where almost none of 
the modern Neotropic ichneumonid fauna has penetrated, would be expected to flourish in the absence of aggressive competitors; whereas, populations in an area such as the Selva Tucumano-Boliviana, where occur scores of the Neotropic genera represented by hundreds of species, would form a much more inconspicuous part of the fauna and might have difficulty surviving at all.

Field Notes: All localities for this species belong to the wet subtropical forest community commonly designated Selva TucumanoBoliviana. Horco Molle in Tucumán Province is located in the lower stratum of this forest (about $700 \mathrm{~m}$.), while Posta de Lozano in Jujuy Province is at $1600 \mathrm{~m}$. in an area of transition between several types of environment, including many components of the Selva and some Chaco elements, as well as stands of alders (Alnus jorullensis).

Specimens of $A$. tucumana were collected by sweeping in weedy areas both at the edge of the forest and in partially shaded places within the forest.

\section{Acknowledgements}

Part of the material covered in this study was collected while the author was working as Associate Investigator under a United States National Science Foundation Grant (GB-6925) awarded to Dr. Howard E. Evans of the Museum of Comparative Zoology at Harvard University.

The figure was inked by Miss Alicia Sandoval of the Instituto Miguel Lillo.

\section{REFERENCES}

Purter, C. C.

1967. A Review of the Chilean genera of the tribe Mesostenini. Studia Ent. $10: 369-418$.

1970. The Genus Anacis in Argentina. Acta Zoologica Lilloana $26(2): 9-22$.

Townes, H. K.

1969. Genera of Ichneumonidae, Part 2, Gelinae. Mem. Amer. Ent. Inst. 12. 

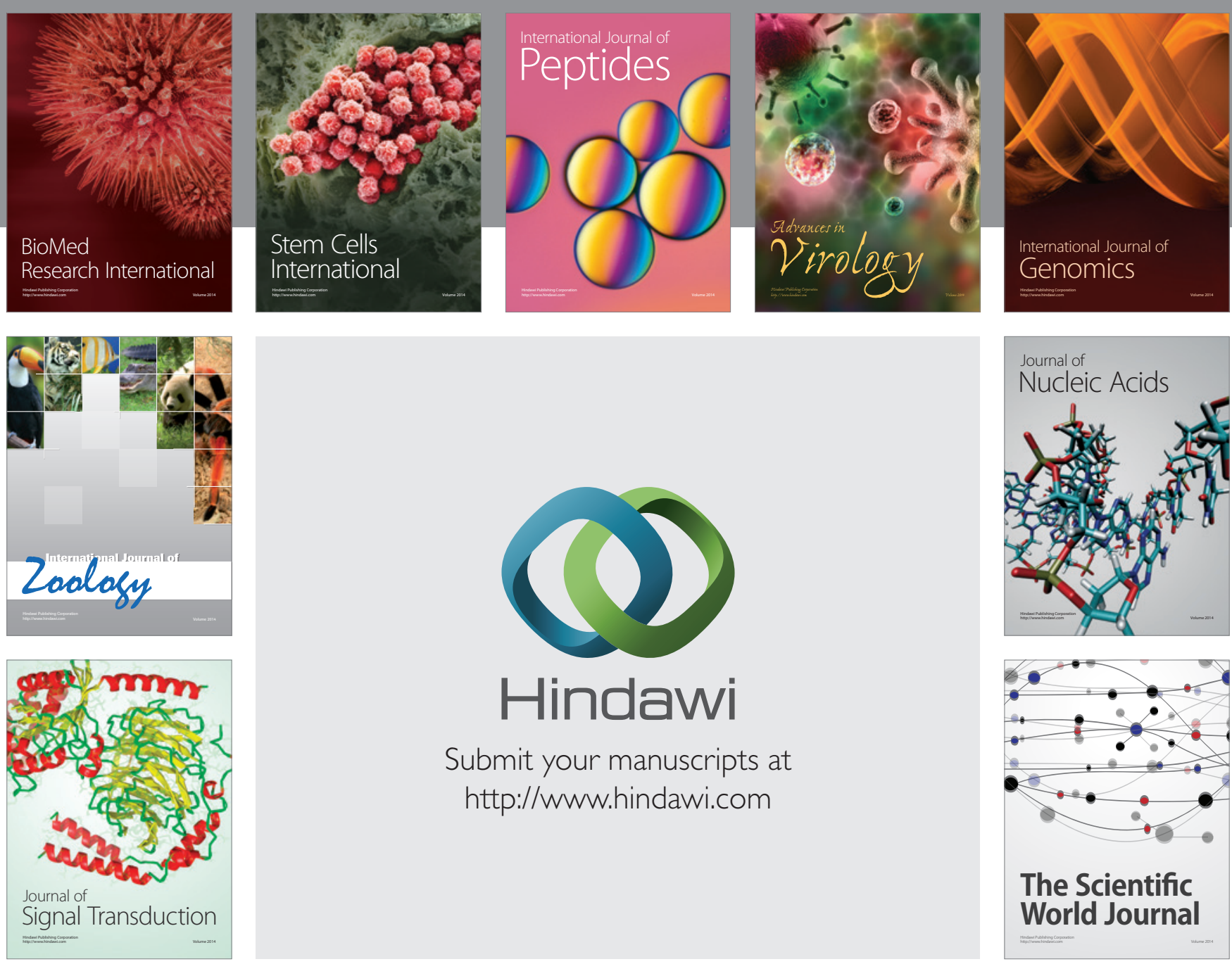

Submit your manuscripts at

http://www.hindawi.com
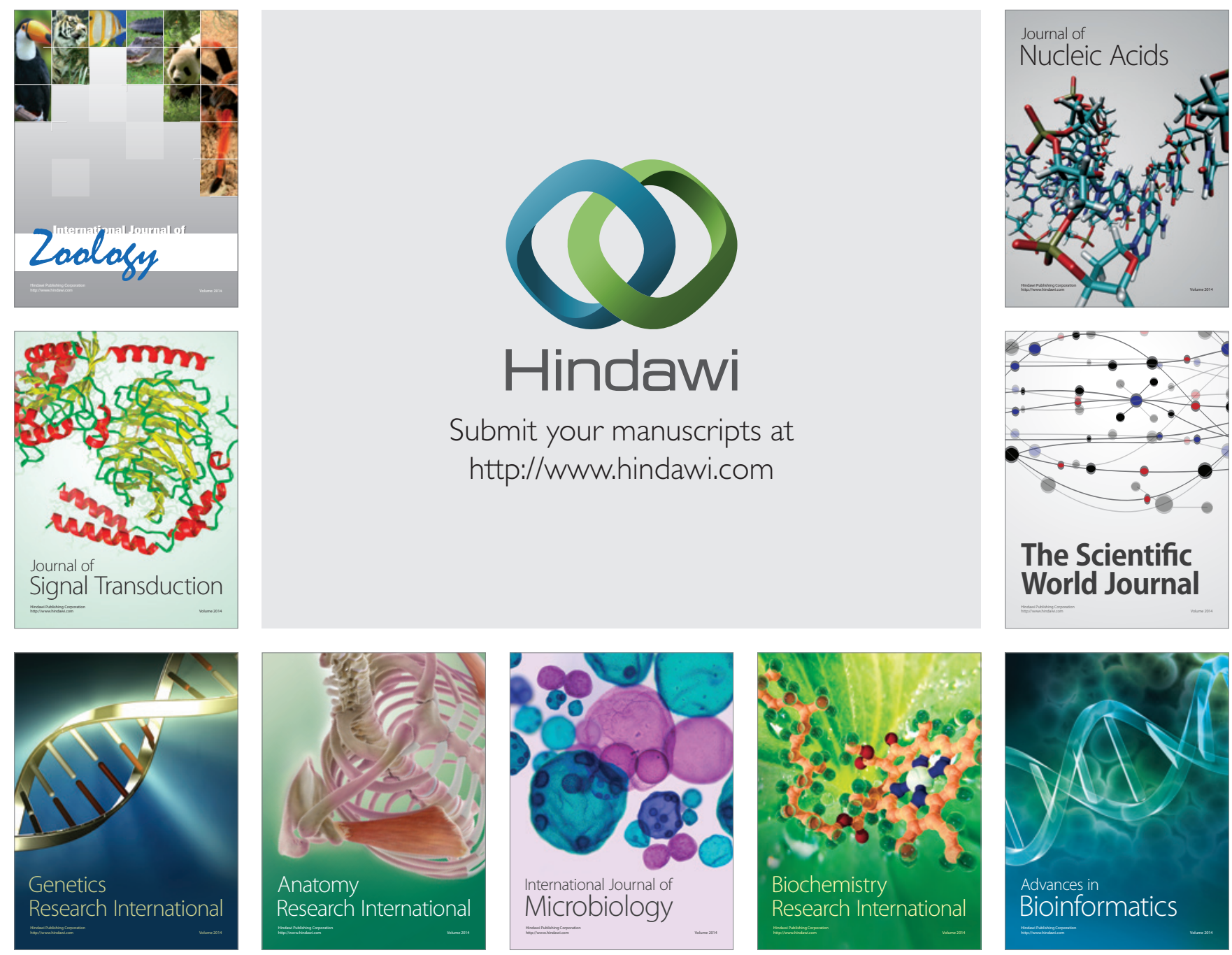

The Scientific World Journal
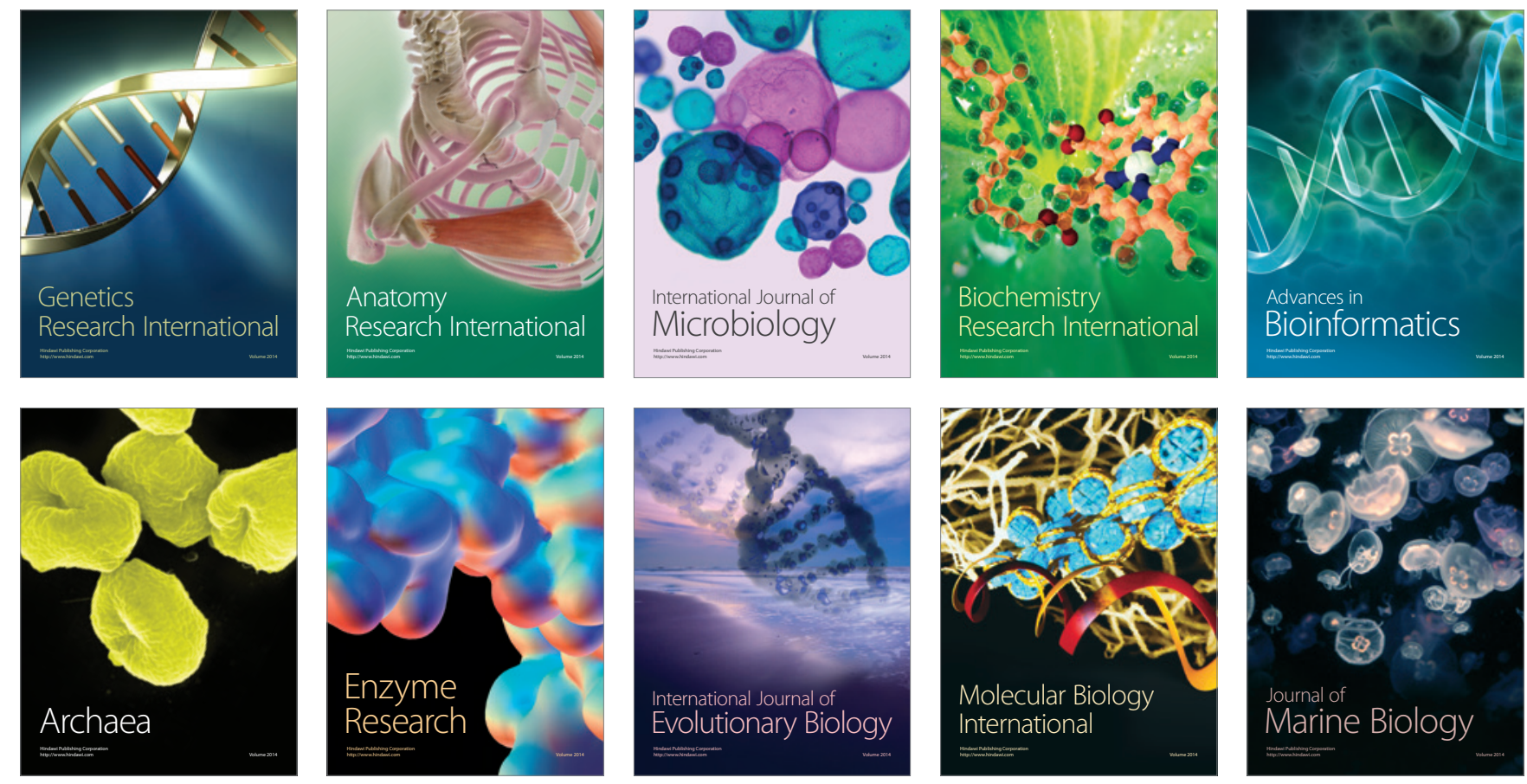